HEFAT2012

$9^{\text {th }}$ International Conference on Heat Transfer, Fluid Mechanics and Thermodynamics

16 - 18 July 2012

Malta

\title{
COMPUTATION OF GAS AND MULTIPHASE SUPERSONIC JETS WITH NON- EQUILIBRIUM PROCESSES
}

\author{
Zavelevich F.S., Molchanov A.M.* and Ushakov N.N. \\ *Author for correspondence \\ Department of Aerospace Heating Engineering, \\ Moscow Aviation Institute, \\ 4, Volokolamskoe Shosse, Moscow \\ Russia, \\ E-mail: alexmol_2010@mail.ru
}

\section{ABSTRACT}

A computational model for simulation of compressible multiphase supersonic jets with non-equilibrium physical and chemical processes is developed. Compared with the others, this model is distinguishes by an extended system of nonequilibrium chemical reactions while taking into account the multiphase non-equilibrium. Lagrangian particle methodology was used. The particle phase change is simulated kinetically and included two solid $\mathrm{Al}_{2} \mathrm{O}_{3}$ crystalline structures: meta stable gamma and stable alpha forms. The simulation results were compared with the available results of the other authors. There was a satisfactory agreement regarding the results of the main gaseous component concentrations. Comparison of the simulation results with experimental data also showed their satisfactory agreement.

\section{INTRODUCTION}

Simulation of rocket exhaust flow fields is essential for assessments of the missile base heat transfer to ensure the motor's health and survival. Gas and multiphase gas/particle flow-field simulations are also an important element of efforts to predict liquid and solid-propellant rocket motor effluents for environmental studies including space debris.

The task for simulation of the gas-dynamic parameters of gas and two-phase jets was solved in the most rigorous formulation. Using the extended system of chemical reactions allowed us to obtain more accurate data on the concentrations of such important components of the gas mixture as $\mathrm{NO}, \mathrm{NO}_{2}$, $\mathrm{ClO}$.

Usually at the altitudes below $15-20 \mathrm{~km}$ the assumption of equilibrium for a two-phase mixture and the chemical equilibrium is fairy true. In the range of heights $20-40 \mathrm{~km}$ the intensity of afterburning processes is drastically reduced. In this range there appears an effect of nonequilibrium flow of "gas + particle" mix. The non-equilibrium effects are greater if the combustion products mass flow (thrust) of the engines is lower.

Non-equilibrium flow of particles and gas delays the afterburning process and results in the shift of afterburning cessation. The use of the extended system of chemical reactions, i.e. introducing 12 reactions with chlorine components, results in temperature lowering in the jet and also in the shift of afterburning cessation. The lower mass flow, the lower is the altitude of afterburning cessation.

\section{NOMENCLATURE}

\begin{tabular}{|c|c|c|}
\hline$a$ & {$[\mathrm{~m} / \mathrm{s}]$} & Speed of sound \\
\hline$B_{k}, F_{k}$ & & $\begin{array}{l}\text { Backward and Forward reaction rate coefficients in } \\
\text { reaction } k\end{array}$ \\
\hline E & {$\left[\mathrm{m}^{2} / \mathrm{s}^{2}\right]$} & Total energy \\
\hline$F_{C}, G_{C}$ & & $x$ and $y$ direction inviscid fluxes \\
\hline$F_{V}, G_{V}$ & & $x$ and $y$ direction viscous fluxes \\
\hline$H$ & {$\left[\mathrm{~m}^{2} / \mathrm{s}^{2}\right]$} & Total enthalpy \\
\hline$h$ & {$\left[\mathrm{~m}^{2} / \mathrm{s}^{2}\right]$} & Enthalpy \\
\hline$h_{I}$ & {$\left[\mathrm{~m}^{2} / \mathrm{s}^{2}\right]$} & Species enthalpy \\
\hline$J_{I, i}$ & {$\left[\mathrm{~kg} /\left(\mathrm{m}^{2} \mathrm{~s}\right)\right]$} & Species diffusion flux \\
\hline$K$ & {$\left[\mathrm{~m}^{2} / \mathrm{s}^{2}\right]$} & Turbulent kinetic energy \\
\hline$L$ & {$[-]$} & Number of groups of particles \\
\hline$M_{T}$ & {$[-]$} & Turbulent Mach Number \\
\hline$m_{\alpha}$ & {$[\mathrm{kg}]$} & The mass of one particle sized $r_{\alpha}$ \\
\hline$N_{C}$ & {$[-]$} & Number of species \\
\hline$n_{\alpha}$ & {$\left[1 / \mathrm{m}^{3}\right]$} & number of particles sized $r_{\alpha}$ per unit volume \\
\hline $\operatorname{Pr}_{T}$ & {$[-]$} & Turbulent Prandtl number \\
\hline$p$ & {$[\mathrm{~Pa}]$} & Pressure \\
\hline$R$ & {$[\mathrm{~J} /(\mathrm{kmol} \cdot \mathrm{K})]$} & Universal gas constant \\
\hline$r_{\alpha}$ & {$[\mathrm{m}]$} & The radius of particle group $\alpha$ \\
\hline$S$ & & Source vector \\
\hline$S_{I}$ & {$\left[\mathrm{~kg} /\left(\mathrm{m}^{3} \mathrm{~s}\right)\right]$} & Species rate of production \\
\hline$S c_{T}$ & {$[-]$} & Turbulent Schmidt number \\
\hline$T$ & {$[\mathrm{~K}]$} & Temperature \\
\hline$T_{\alpha}$ & {$[\mathrm{K}]$} & Temperature of particle group $\alpha$ \\
\hline$U$ & & Conservative variable vector \\
\hline$u, v$ & {$[\mathrm{~m} / \mathrm{s}]$} & Velocity components \\
\hline
\end{tabular}




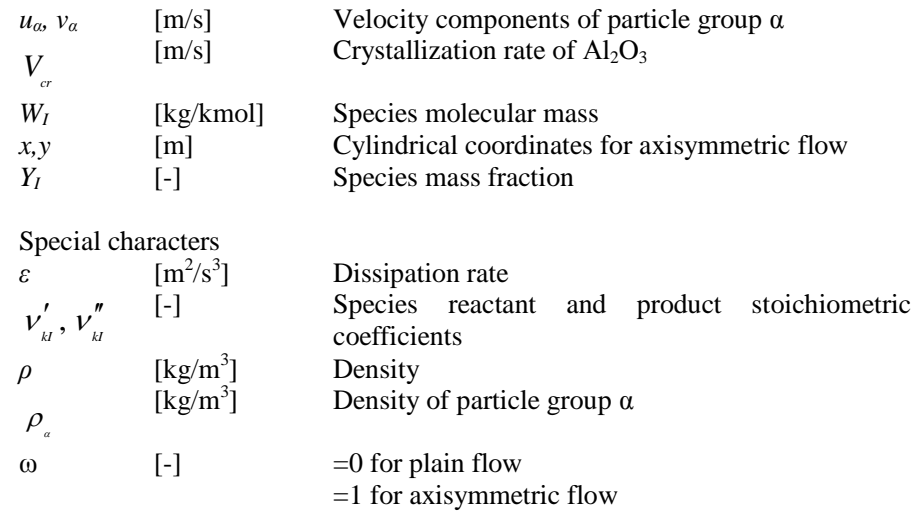

The basic assumptions for the gas-dynamic model of the plume and simulation methods at the heights of $0-90 \mathrm{~km}$ are as follows:

1. The composite stream is replaced with an equivalent single axisymmetric jet.

2. The flow of gas in the jet is described by the complete system of Navier-Stokes [1] (see The governing gasphase equations);

3. The extended system of chemical reactions is used for non-equilibrium chemical processes (for a system that contains $\mathrm{C}, \mathrm{O}, \mathrm{H}, \mathrm{N}, \mathrm{C} 1$, consisting of 42 reactions) [1-4] (see Table);

4. Non-equilibrium of particles and gas is considered in the complete statement: temperature, speed, phase for particles (liquid and solid states $(\alpha-, \gamma$-phase)), crystallization for particles (see Particle flow equations).

\section{THE GOVERNING GAS-PHASE EQUATIONS}

The set of Favre averaged equations for high Reynolds twodimension turbulent reacting flow can be cast in the following compact form:

$$
\frac{\partial U}{\partial t}+\frac{\partial F_{c}}{\partial x}+\frac{\partial G_{c}}{\partial y}+\frac{\omega}{y} H_{c}+\frac{\partial F_{v}}{\partial x}+\frac{\partial G_{v}}{\partial y}+\frac{\omega}{y} H_{v}=S,
$$

where

$$
\begin{gathered}
U=\left[\rho, \rho u, \rho v, \rho E, \rho Y_{1}, \ldots, \rho Y_{N c-1}, \rho K, \rho \varepsilon\right]^{T}, \\
F_{c}=\left(\begin{array}{l}
\rho u \\
\rho u^{2}+p \\
\rho u v \\
u(\rho E+p) \\
\rho u Y_{1} \\
\ldots \\
\rho u Y_{N c-1} \\
\rho u K \\
\rho u \varepsilon
\end{array}\right), G_{C}=\left(\begin{array}{l}
\rho v \\
\rho v^{2}+p \\
v(\rho E+p) \\
\rho v Y_{1} \\
\ldots \\
\rho v Y_{N c-1} \\
\rho v K \\
\rho v \varepsilon
\end{array}\right), H_{C}=\left(\begin{array}{l}
\rho v \\
\rho u v \\
\rho v^{2} \\
v(\rho E+p) \\
\rho v Y_{1} \\
\ldots \\
\rho v Y_{N c-1} \\
\rho v K \\
\rho v \varepsilon
\end{array}\right)
\end{gathered}
$$

$$
\begin{aligned}
& F_{V}=\left(\begin{array}{l}
0 \\
-T_{x x} \\
-T_{y x} \\
Q_{x} \\
-u T_{x x}-v T_{y x} \\
J_{1, x} \\
\ldots \\
J_{N c-1, x} \\
J_{K, x} \\
J_{\varepsilon, x}
\end{array}\right), G_{V}=\left(\begin{array}{l}
0 \\
-T_{y x} \\
-T_{y y} \\
Q_{y} \\
-u T_{y x}-v T_{y y}
\end{array}\right), H_{1, y}=\left(\begin{array}{l}
0 \\
-T_{y x} \\
\cdots \\
J_{N c-1, y} \\
J_{K, y} \\
J_{\varepsilon, y}
\end{array}\right)\left(\begin{array}{l}
T_{y y}+T_{\theta \theta} \\
Q_{y} \\
-u T_{y x}-v T_{y y} \\
J_{1, y} \\
\ldots \\
J_{N c-1, y} \\
J_{K, y} \\
J_{\varepsilon, y} \\
\end{array}\right), \\
& S=\left[0, S_{u}, S_{v}, S_{E}, S_{1}, \ldots, S_{N c-1}, S_{K}, S_{\varepsilon}\right]^{T}
\end{aligned}
$$

The Reynolds stress tensors and the enthalpy, species, $K, \varepsilon$ turbulent fluxes are closed by the classical Boussinesq-like formulation for non-zero divergence flows:

$$
\begin{aligned}
& T_{x x}=\frac{2 \mu_{T}}{3}\left[2 \frac{\partial u}{\partial x}-\frac{\partial v}{\partial y}-\frac{\omega}{y} v\right]-\frac{2}{3} \rho K \\
& T_{y y}=\frac{2 \mu_{T}}{3}\left[-\frac{\partial u}{\partial x}+2 \frac{\partial v}{\partial y}-\frac{\omega}{y} v\right]-\frac{2}{3} \rho K \\
& T_{x y}=\mu_{T}\left(\frac{\partial u}{\partial y}+\frac{\partial v}{\partial x}\right), \\
& T_{\theta \theta}=\frac{2}{3} \mu_{T}\left(-\frac{\partial u}{\partial x}+2 \frac{\omega}{y} v-\frac{\partial v}{\partial y}\right)-\frac{2}{3} \rho K \\
& Q_{x}=-\frac{\mu_{T}}{\operatorname{Pr}_{T}} \frac{\partial h}{\partial x}+\mu_{T} \sum_{I=1}^{N_{c}}\left(\frac{1}{\operatorname{Pr}_{T}}-\frac{1}{\mathrm{Sc}_{T, I}}\right) h_{I} \frac{\partial Y_{I}}{\partial x} \\
& Q_{y}=-\frac{\mu_{T}}{\operatorname{Pr}_{T}} \frac{\partial h}{\partial y}+\mu_{T} \sum_{I=1}^{N_{c}}\left(\frac{1}{\operatorname{Pr}_{T}}-\frac{1}{\mathrm{Sc}_{T, I}}\right) h_{I} \frac{\partial Y_{I}}{\partial y} \\
& J_{K y}=-\frac{\mu_{T}}{\sigma_{K}} \frac{\partial K}{\partial y}, \quad J_{\varepsilon y}=-\frac{\mu_{T}}{\sigma_{\varepsilon}} \frac{\partial \varepsilon}{\partial y} \\
& J_{I, x} \frac{\mu_{I}}{\partial x}, \quad J_{I, y}=-\frac{\partial Y_{I}}{\operatorname{Sc}_{T, I}} \frac{\partial y}{\partial y}, \quad J_{\varepsilon x}=-\frac{\mu_{T}}{\partial \varepsilon} \\
& =
\end{aligned}
$$

Additional equations:

$$
\begin{aligned}
& \sum_{1}^{N c} Y_{I}=1, \quad h=\sum_{I=1}^{N c} h_{I} Y_{I}, \\
& H=\sum_{I=1}^{N c} h_{I} Y_{I}+\frac{1}{2}\left(u^{2}+v^{2}\right), \quad E=H-\frac{p}{\rho}
\end{aligned}
$$


For a high temperature, chemically reacting flow, the gas is assumed to be thermally perfect:

$$
p=\rho T R \sum_{I=1}^{N_{c}} \frac{Y_{I}}{W_{I}}
$$

The species specific heat and enthalpies are obtained from the following equations [9]:

$\frac{C_{P, I}(T)}{R}=a_{1, I}+a_{2, I} T+a_{3, I} T^{2}+a_{4, I} T^{3}+a_{5, I} T^{4}$,

$\frac{h_{I}(T)}{R T}=a_{1, I}+a_{2, I} \frac{T}{2}+a_{3, I} \frac{T^{2}}{3}+a_{4, I} \frac{T^{3}}{4}+a_{5, I} \frac{T^{4}}{5}+\frac{b_{1, I}}{T}$

The members $S_{u}, S_{v}, S_{E}$ comprised in the source $S$ take into account the effect of particles on the gas parameters:

$$
\begin{aligned}
& S_{u}=-\sum_{\alpha=1}^{L} f_{\alpha, x} ; \quad S_{v}=-\sum_{\alpha=1}^{L} f_{\alpha, y} ; \\
& S_{E}=\sum_{\alpha=1}^{L}\left(q_{c o n v, \alpha}-f_{\alpha, x} u_{\alpha}-f_{\alpha, y} v_{\alpha}\right)
\end{aligned}
$$

(described in Particle flow equations section).

The members $S_{1}, \ldots, S_{N c-1}$ are defined by species rates of production (see Chemical Kinetics). And, at last, $S_{K}, S_{\varepsilon}$ are defined by the turbulence model (see Turbulence model).

\section{TURBULENCE MODEL}

The transport equations for $K$ and $\varepsilon$ for high Reynolds numbers are as follows [1]:

$$
\begin{aligned}
& \frac{\partial}{\partial t}(\bar{\rho} K)+\frac{\partial}{\partial x_{j}}\left(\bar{\rho} \tilde{u}_{j} K\right)=\frac{\partial}{\partial x_{j}}\left[\frac{\mu_{T}}{\sigma_{K}} \frac{\partial K}{\partial x_{j}}\right] \\
& +\mathrm{P}_{K}-\left[1+\varphi\left(M_{T}\right)\right] \bar{\rho} \varepsilon \quad, \\
& \frac{\partial}{\partial t}(\bar{\rho} \varepsilon)+\frac{\partial}{\partial x_{j}}\left(\bar{\rho} \tilde{u}_{j} \varepsilon\right)=\frac{\partial}{\partial x_{j}}\left[\left(\frac{\mu_{T}}{\sigma_{\varepsilon}}+\mu\right) \frac{\partial \varepsilon}{\partial x_{j}}\right] \\
& +\frac{\varepsilon}{K}\left(C_{\varepsilon 1} \mathrm{P}_{K}-C_{\varepsilon 2} \bar{\rho} \varepsilon\right)
\end{aligned}
$$

which use standard constant pool:

$\sigma_{K}=1 ; \quad \sigma_{\varepsilon}=1.3 ; \quad C_{\varepsilon 1}=1.44 ; \quad C_{\varepsilon 2}=1.92$

In these equations $P_{K}$ is the production term,

$M_{T}$ - Mach turbulent number

$$
M_{T}=\frac{\sqrt{2 K}}{a}
$$

$a$ - local sound speed. $\varphi\left(M_{T}\right)$ - compressibility function:

$$
\varphi\left(M_{T}\right)=C_{M} M_{T}
$$

This paper uses the modification of $K-\varepsilon$ turbulence model based on the analysis of transport equations for Reynolds stress.
Assuming that diffusion and convection are balanced in these equations, the following formula for turbulent viscosity can be obtained

$$
\mu_{T}=\frac{\left(1-C_{2}\right)}{C_{1}} \frac{V_{n}^{\prime \prime 2}}{K} \cdot \bar{\rho} \frac{K^{2}}{\varepsilon}=C_{\mu} \bar{\rho} \frac{K^{2}}{\varepsilon},
$$

where

$$
C_{\mu}=\frac{\left(1-C_{2}\right)}{C_{1}} \frac{V_{n}^{\prime \prime 2}}{K},
$$

$V_{n}^{\prime \prime}$ - velocity fluctuation normal to the streamlines, for which it is true:

$$
\frac{V_{n}^{\prime \prime 2}}{K}=\frac{2}{3}\left\{1-\frac{\left(1-C_{2}\right)}{C_{1}}\left[1+\varphi\left(M_{T}\right)\right]\right\},
$$

The following numerical constants are used:

$$
C_{1}=1.8 ; \quad C_{2}=0.6
$$

Thus, unlike standard $K-\varepsilon$ turbulence model, the presented model firstly includes supplementary dissipation dependable on the turbulent Mach number $M_{T}$, and secondly the coefficient $C_{\mu}$ in formula (15) of turbulent viscosity is no longer constant but dependable on $M_{T}$ as well.

The following constant is used in formula(14) for this model:

$$
C_{M}=0.4
$$

\section{CHEMICAL KINETICS}

Finite rate chemical kinetics is used to track chemical reactions in the present work. This method is based on the Law of Mass Action.

The production rate of each species is given by:

$$
S_{I}=W_{I} \sum_{k=1}^{K}\left(v_{k I}^{\prime \prime}-v_{k I}^{\prime}\right) R_{k}
$$

The Law of Mass Action for $k$-th reaction is:

$$
R_{k}=\left(F_{k} \prod_{I=A, B, \ldots}^{N_{C}}[I]^{v_{k I}^{\prime}}-B_{k} \prod_{I=A, B, \ldots}^{N_{C}}[I]^{v_{k I}^{\prime \prime}}\right)
$$

It is very important to select properly chemical reaction rate coefficients. The available data on these coefficients were obtained in the conditions that are considerably different from those of rocket engines jets having a greater dispersion characterized by the uncertainty factor.

After comparing the simulated and experimental data on the characteristics of jets of real and model rocket engines, the coefficients for reactions 1-20 were selected, within the limits of the uncertainty factor (see table), which provided the best agreement between the simulation and experimental data. 
Table

The system of non-equilibrium chemical reactions

\begin{tabular}{|c|c|c|c|}
\hline No. & Reaction & No. & Reaction \\
\hline 1 & $\mathrm{CO}+\mathrm{OH}=\mathrm{CO}_{2}+\mathrm{H}$ & 22 & $\mathrm{~N}+\mathrm{O}_{2}=\mathrm{O}+\mathrm{NO}$ \\
\hline 2 & $\mathrm{OH}+\mathrm{H}_{2}=\mathrm{H}_{2} \mathrm{O}+\mathrm{H}$ & 23 & $\mathrm{~N}+\mathrm{OH}=\mathrm{H}+\mathrm{NO}$ \\
\hline 3 & $\mathrm{H}+\mathrm{O}_{2}=\mathrm{OH}+\mathrm{O}$ & 24 & $\mathrm{H}+\mathrm{O}+\mathrm{M}=\mathrm{OH}+\mathrm{M}$ \\
\hline 4 & $\mathrm{O}+\mathrm{H}_{2}=\mathrm{OH}+\mathrm{H}$ & 25 & $\mathrm{~N}+\mathrm{O}+\mathrm{M}=\mathrm{NO}+\mathrm{M}$ \\
\hline 5 & $\mathrm{H}+\mathrm{O}_{2}+\mathrm{M}=\mathrm{HO}_{2}+\mathrm{M}$ & 26 & $\mathrm{O}_{2}+\mathrm{N}_{2}=2 \mathrm{NO}$ \\
\hline 6 & $\mathrm{OH}+\mathrm{HO}_{2}=\mathrm{H}_{2} \mathrm{O}+\mathrm{O}_{2}$ & 27 & $\mathrm{HO}_{2}+\mathrm{NO}=\mathrm{NO}_{2}+\mathrm{OH}$ \\
\hline 7 & $\mathrm{H}+\mathrm{HO}_{2}=2 \mathrm{OH}$ & 28 & $\mathrm{O}+\mathrm{NO}_{2}=\mathrm{NO}+\mathrm{O}_{2}$ \\
\hline 8 & $\mathrm{O}+\mathrm{HO}_{2}=\mathrm{O}_{2}+\mathrm{OH}$ & 29 & $\mathrm{NO}_{2}+\mathrm{H}=\mathrm{NO}+\mathrm{OH}$ \\
\hline 9 & $2 \mathrm{OH}=\mathrm{O}+\mathrm{H}_{2} \mathrm{O}$ & 30 & $\mathrm{ClO}+\mathrm{NO}=\mathrm{NO}_{2}+\mathrm{Cl}$ \\
\hline 10 & $\mathrm{H}+\mathrm{HO}_{2}=\mathrm{H}_{2}+\mathrm{O}_{2}$ & 31 & $\mathrm{Cl}+\mathrm{O}_{3}=\mathrm{ClO}+\mathrm{O}_{2}$ \\
\hline 11 & $\mathrm{CO}+\mathrm{O}+\mathrm{M}=\mathrm{CO}_{2}+\mathrm{M}$ & 32 & $\mathrm{ClO}+\mathrm{OH}=\mathrm{HO}_{2}+\mathrm{Cl}$ \\
\hline 12 & $2 \mathrm{H}+\mathrm{M}=\mathrm{H}_{2}+\mathrm{M}$ & 33 & $\mathrm{Cl}+\mathrm{HO}_{2}=\mathrm{HCl}+\mathrm{O}_{2}$ \\
\hline 13 & $\mathrm{H}+\mathrm{OH}+\mathrm{M}=\mathrm{H}_{2} \mathrm{O}+\mathrm{M}$ & 34 & $\mathrm{HCl}+\mathrm{OH}=\mathrm{Cl}+\mathrm{H}_{2} \mathrm{O}$ \\
\hline 14 & $2 \mathrm{HO}_{2}=\mathrm{H}_{2} \mathrm{O}_{2}+\mathrm{O}_{2}$ & 35 & $\mathrm{HCl}+\mathrm{O}=\mathrm{OH}+\mathrm{Cl}$ \\
\hline 15 & $\mathrm{H}_{2} \mathrm{O}_{2}+\mathrm{M}=2 \mathrm{OH}+\mathrm{M}$ & 36 & $\mathrm{H}_{2}+\mathrm{Cl}=\mathrm{HCl}+\mathrm{H}$ \\
\hline 16 & $\mathrm{H}_{2} \mathrm{O}_{2}+\mathrm{H}=\mathrm{HO}_{2}+\mathrm{H} 2$ & 37 & $\mathrm{H}+\mathrm{Cl}+\mathrm{M}=\mathrm{HCl}+\mathrm{M}$ \\
\hline 17 & $\mathrm{H}_{2} \mathrm{O}_{2}+\mathrm{OH}=\mathrm{H}_{2} \mathrm{O}+\mathrm{HO}_{2}$ & 38 & $\mathrm{H}+\mathrm{Cl}_{2}=\mathrm{HCl}+\mathrm{Cl}$ \\
\hline 18 & $2 \mathrm{O}+\mathrm{M}=\mathrm{O}_{2}+\mathrm{M}$ & 39 & $\mathrm{M}+2 \mathrm{Cl}=\mathrm{Cl}_{2}+\mathrm{M}$ \\
\hline 19 & $\mathrm{H}+\mathrm{H}_{2} \mathrm{O}_{2}=\mathrm{H}_{2} \mathrm{O}+\mathrm{OH}$ & 40 & $\mathrm{Cl}_{2}+\mathrm{OH}=\mathrm{HOCl}+\mathrm{Cl}$ \\
\hline 20 & $\mathrm{O}+\mathrm{H}_{2} \mathrm{O}_{2}=\mathrm{OH}+\mathrm{HO}_{2}$ & 41 & $\mathrm{HOCl}+\mathrm{OH}=\mathrm{H}_{2} \mathrm{O}+\mathrm{ClO}$ \\
\hline
\end{tabular}

Figure 1 shows a comparison of calculation results of the combustion products mass flow rates along the jet axis (solid lines) with the calculations given in [3] (dashed lines) for the intermediate-thrust rocket $\sim 80$ ton.

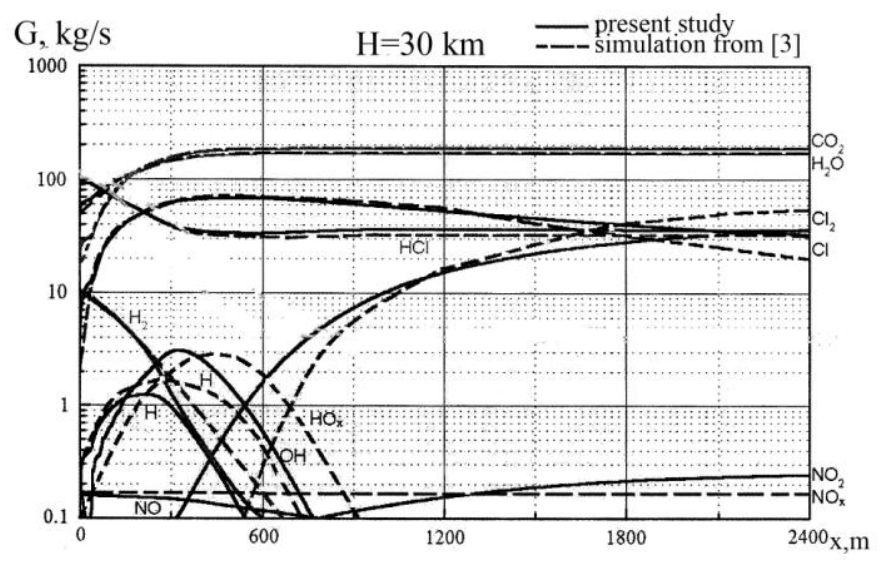

Figure 1 Axial distributions of species mass flow rates

There was a good agreement of the results for the main components of the jet. The non-compliance of $\mathrm{NO}$ and $\mathrm{NO}_{\mathrm{X}}$ rates accounted for the differences in the set of the chemical reactions. The present method used the chemical reactions with chlorine-containing components from [3] (see table). However, this work did not take into account a number of reactions with component $\mathrm{HO}_{2}$, provided in the table, which, according to the analysis, significantly impact on the concentration of molecules $\mathrm{ClO}$ (reaction 32). The developed method takes into account 12 reactions with $\mathrm{HO}_{2}$. The concentration of molecules $\mathrm{ClO}$ impacts on the transfer process of molecules $\mathrm{NO}$ into $\mathrm{NO}_{2}$ (reaction 30).
Figure 2 shows the additional comparison of the concentrations of $\mathrm{HO}_{2}, \mathrm{ClO}, \mathrm{NO}$ and $\mathrm{NO}_{2}$. The dotted lines show the calculations with a modified system of reactions without $\mathrm{HO}_{2}$ reactions and with rate coefficients taken from [3].

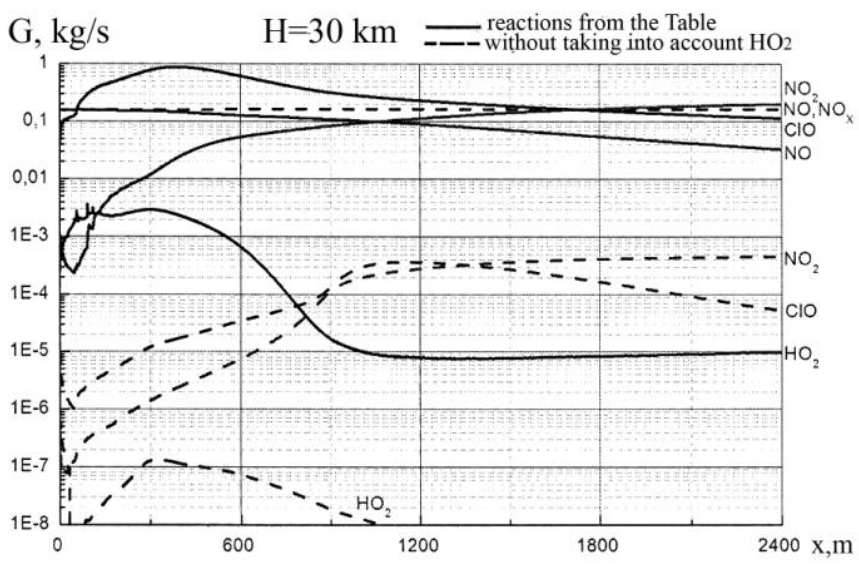

Figure 2 Axial distributions of species mass flow rates

As seen, there are significant differences from the basis computation of concentrations of $\mathrm{HO}_{2}, \mathrm{ClO}, \mathrm{NO}$ and $\mathrm{NO}_{2}$. Comparing with [3] with the altered system of chemical reactions showed a good agreement of distribution of components mass flow rate of $\mathrm{NO}$ and $\mathrm{NO}_{\mathrm{X}}$ (compare dashed lines $\mathrm{NO}_{\mathrm{X}}$ in Figure 1 and $\mathrm{NO}, \mathrm{NO}_{\mathrm{X}}$ in Figure 2).

The use of the extended system of reactions led to the fact that a considerable part of components NO transfer into NO2 when molecules $\mathrm{NO}$ interacted with $\mathrm{ClO}$ in the jets of solid-fuel rocket engines containing chlorine-containing components (i.e., "Space-Shuttle" launch vehicle and "Titan" launch vehicle). This transfer of NO into $\mathrm{NO}_{2}$ did not happen in the jets of liquid rocket engines (i.e., "Proton" launch vehicle) due to the absence of chlorine-containing components.

Based on the computation results of distribution of component concentrations in the end of the jet of "SpaceShuttle" and "Titan" Professor I.L. Karol performed computations of concentration component variance in the jet wake, which were presented in [5]. The results were compared with the data of [6] on the variance of $\mathrm{Cl}_{2}$ concentration in the wake. For the "Titan" the computation results for night launch are shown in Figure 3. There was a good agreement with the variance of $\mathrm{Cl}_{2}$ concentration (marked by (*) in Figure 3 ). 


\section{$\mathrm{q}, \mathrm{mole} / \mathrm{cm}^{3}$}

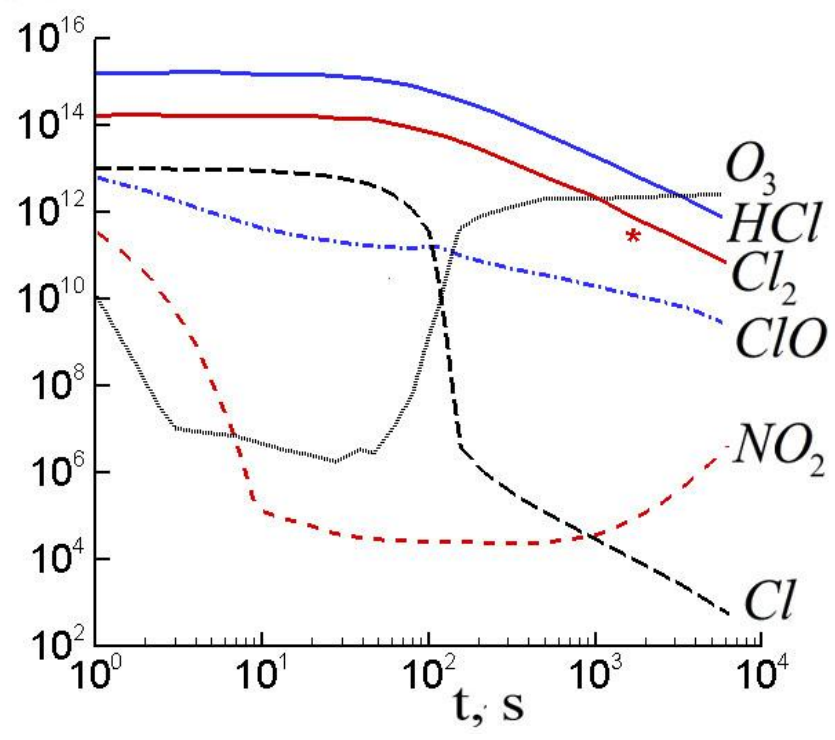

Figure 3 Variance of the combustion products components concentrations along the center line of a cold wake

\section{PARTICLE FLOW EQUATIONS}

Polydisperse mixture of particles is represented as a set of $L$ groups of particles, each of which is characterized by the values of the radius $r_{\alpha}$, density $\rho_{\alpha}=n_{\alpha} \cdot m_{\alpha}$, velocity components $u_{\alpha}, v_{\alpha}$, and temperature $T_{\alpha}$.

For each of $L$ groups $(\alpha=1,2, \ldots L)$, under the assumptions that the particles are spherical, chemically inert to the gaseous phase, and do not interact with each other, equations describing the motion of $\mathrm{Al} 2 \mathrm{O} 3$ particles can be written as:

1) Particle continuity:

$$
\frac{\partial}{\partial x}\left(\rho_{\alpha} u_{\alpha} y\right)+\frac{\partial}{\partial y}\left(\rho_{\alpha} v_{\alpha} y\right)=0,
$$

2) Particle momentum in $x$ direction:

$$
\rho_{\alpha} u_{\alpha} \frac{\partial u_{\alpha}}{\partial x}+\rho_{\alpha} v_{\alpha} \frac{\partial u_{\alpha}}{\partial y}=f_{\alpha, x}
$$

3) Particle momentum in $y$ direction $(\alpha=1,2, \ldots L)$ :

$$
\rho_{\alpha} u_{\alpha} \frac{\partial v_{\alpha}}{\partial x}+\rho_{\alpha} v_{\alpha} \frac{\partial v_{\alpha}}{\partial y}=f_{\alpha, y}
$$

4) Particle energy:

$$
\begin{aligned}
& \rho_{\alpha} u_{\alpha} C_{S} \frac{\partial T_{\alpha}}{\partial x}+\rho_{\alpha} v_{\alpha} C_{S} \frac{\partial T_{\alpha}}{\partial y} \\
& =q_{\text {phase }, \alpha}-q_{\text {conv }, \alpha}-q_{\text {rad }, \alpha}
\end{aligned}
$$

As a result of crystallization, the following is true for a heat flow:

$$
q_{p h a s e, \alpha}=3 q_{c r} \frac{r_{c r, \alpha}{ }^{2}}{r_{\alpha}^{3}} V_{c r}
$$

where $q_{c r}$ - the heat of crystallization, $V_{c r}$ - crystallization rate, $r_{c r, \alpha}-$ the position of the crystallization front.

It is supposed that particles start crystallizing when their temperature is equal to $0,82 T_{L} \quad\left(T_{L}\right.$ - the equilibrium melting point of $\gamma$-phase equal to $2300 \mathrm{~K}$ ).

According to [7] the crystallization rate of $\mathrm{Al}_{2} \mathrm{O}_{3}$ particles is calculated by the formula

$$
V_{c r}=0.64 \cdot 10^{-6}\left(T_{L}-T_{\alpha}\right)^{1.8}, \mathrm{~m} / \mathrm{s}
$$

and the position of crystallization front is defined from the equation

$$
\frac{d r_{c r, \alpha}}{d t}=-V_{c r}
$$

(crystallization front moves toward the center of the particle).

The liquid phase is assumed to transfer initially to the metastable solid $\gamma$-phase for all conditions. The transition process from the $\gamma$-phase to the stable $\alpha$-phase begins as soon as any portion of the $\gamma$-phase has appeared.

To determine the portion of solid substance in the $\alpha$-phase $\left(f_{\alpha}\right)$ the following equation is applied [8]:

$$
\frac{d f_{\alpha}}{d t}=A \cdot \exp \left(-B / T_{\alpha}\right), \quad 0<f_{\alpha}<1
$$

where $\mathrm{A}=1.03 \cdot 10^{12} \mathrm{~s}^{-1}, \mathrm{~B}=58368 \mathrm{~K}$.

\section{PARTICLE EFFECT ON AFTERBURNING}

Fig. 4 demonstrates the axis distributions of the estimated gas temperature with and without considering the particle effect in a jet of typical solid rocket engine with thrust 12 ton at the attitude of $31 \mathrm{~km}$. At that attitude the estimated gas temperature without considering particle effect is so low that chemical reactions do not occur (see dashed line on fig. 4).

When considering the particle effect on gas, the gas estimated temperature increases, which leads to afterburning of products exhausting from the nozzle. At that attitude the effect of chemical reactions with chlorine-containing components on the gas temperature is also noticeable; considering those results in reducing the estimated temperature in the jet (see solid and dashed lines on Figure 4). 


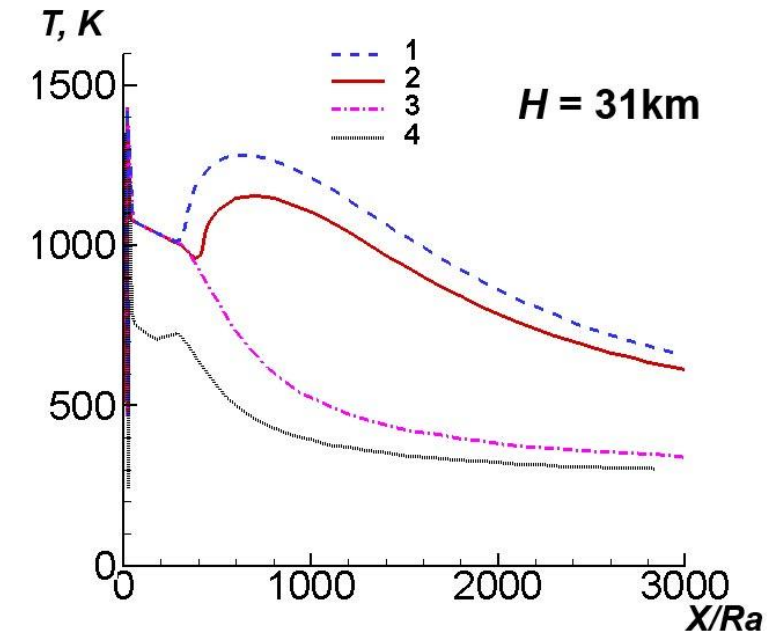

Figure 4 Distribution of gas temperature along jet axis of solid rocket engine with thrust $\sim 12$ ton at attitude of $31 \mathrm{~km}$ :

1 - taking into account the effect of particles and reactions without chlorine-containing components;

2 - taking into account the effect of particles and reactions with chlorine-containing components;

3 - taking into account the effect of particles without chemical reactions;

4 - excluding the effect of particles with and without chemical reactions

For an engine with thrust of 85 ton, non-equilibrium is noticeable at the attitudes $\mathrm{H}=40-45 \mathrm{~km}$, and particularly at the attitude $\mathrm{H}=40 \mathrm{~km}$ (Figure 5), where the jet ceases burning without considering particles on the gas. This brings down the temperature drastically $(\Delta \mathrm{T} \approx 300-600 \mathrm{~K})$ and considerably (in times and orders) change in combustion products concentration.

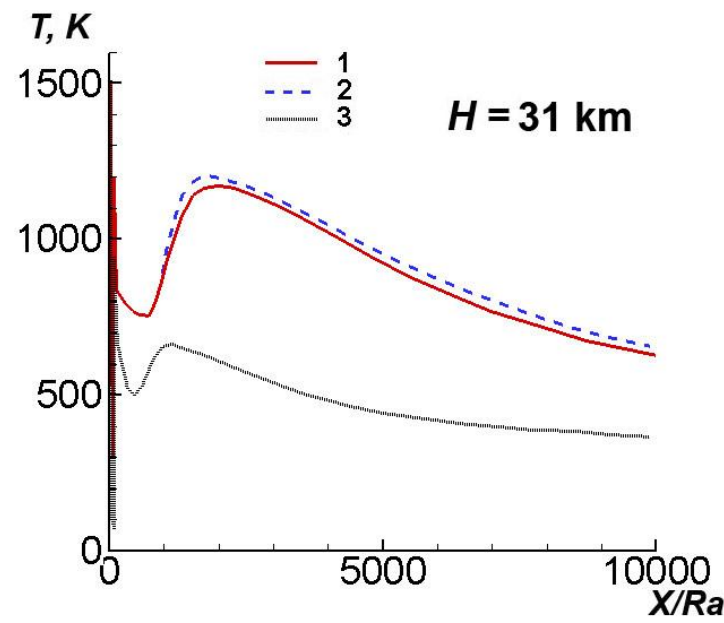

Figure 5 Distribution of gas temperature along jet axis of solid rocket engine with thrust 85 ton at attitude of $40 \mathrm{~km}$ :

1 - taking into account the effect of particles and reactions with chlorine-containing components;

2 - taking into account the effect of particles and reactions without chlorine-containing components;

3 - excluding the effect of particles on the gas
For very large missiles, such as "Space Shuttle", afterburning does not cease during the mid-course burn of rocket engine $(\mathrm{H}<50 \mathrm{~km})$. According to computations taking into account the effect of particles, the concentrations of gas components changed by $25-30 \%$.

Particles intensify afterburning process in the jets and lead to the increase in the attitude of afterburning cessation by 5 $10 \mathrm{~km}$ depending on engine thrusts; on the contrary chemical reactions with chlorine-containing components lead to the decrease in the attitude of afterburning cease by $1-5 \mathrm{~km}$ depending on the engine trust.

\section{Conclusions}

A computational model for simulation of compressible multiphase supersonic jets with non-equilibrium physical and chemical processes is developed.

The simulation results were compared with the available data obtained by the other authors specializing in chemically non-equilibrium jets. There was a satisfactory agreement of the results by the basis gas components of the jet. Comparing the simulation results with the experimental data also showed their good agreement.

Using the extended system of chemical reactions allowed us to obtain more accurate data on the concentrations of such important components of the gas mixture as $\mathrm{NO}, \mathrm{NO} 2, \mathrm{ClO}$.

The range of altitudes $(\mathrm{H}=30-50 \mathrm{~km})$ was determined where the particles and chlorine-containing components reactions effect on the parameters of the gas phase is the most essential. It was shown that the particles intensify the process of burning in jets and increase the altitude of afterburning cessation (5-10 km, depending on the engine thrust); and on the contrary, the chlorine-containing components chemical reactions reduce the altitude of afterburning cessation $(1-5 \mathrm{~km}$ depending on the engine thrust).

In this altitude range the effect of particles on the gas flowfield can lead to substantial increase $(\sim 300-600 \mathrm{~K})$ of the jet temperature and great (in times and orders) changes in component concentrations.

The altitude range where the effect of particles on temperature and species concentrations is significant is highly dependent on the combustion products mass flow. The lower mass flow, the lower is the altitude of afterburning cessation. For very large rockets, such as the "Space Shuttle", the gasparticle interaction causes the change of the component concentrations by $25-30 \%$.

\section{REFERENCES}

[1] Molchanov A.M., Numerical Simulation of Supersonic Chemically Reacting Turbulent Jets, 20th AIAA Computational Fluid Dynamics Conference 27-30 June 2011, Honolulu, Hawaii, AIAA Paper 2011 $3211,37 \mathrm{p}$. 
[2] Gardiner, W.C. Jr. (ed.), Combustion chemistry, Springer-Verlag, New York, 1984, 509 p.

[3] Denison, M.R., Lamb, J.J., Bjorndahl, W.D., Wong, E.Y., Lohn, P.D., Solid Rocket Exhaust in the Stratosphere: Plume Diffusion and Chemical Reactions, Journal of Spacecraft and Rockets. Vol. 31. № 3. 1994m .pp. 435-442.

[4] Hemsh, M.J., Nielsen J.N. (ed), Tactical missile aerodynamics, AIAA, N.Y., 1986, 858p.

[5] Karol, I.L., Ozolin, Yu.E., Zavelevich, F.S., Oushakov, N.N., Rozanov, E.V.. Space Rocket Exhaust Effect on Stratospheric Composition and Ozone. 51st International Astronautical Congress 2-6 Oct 2000/ Rio de Janeiro, Brazil.

[6] Ross, M. N., J. O. Ballenthin, R. B. Gosselin, R. F. meads, P. F. Zittel, J. R. Benbrook, and W. R. Sheldon, In-situ measurement of $\mathrm{Cl} 2$ and $\mathrm{O} 3$ in a stratospheric solid rocket motor exhaust plume, Geophys. Res. Lett., vol. 24, no. 14, 1755-1758, 1997.

[7] Plastinin, Yu.A., Sipachev H.Ph., Karabadzhak G.F., Khmelinin B.A., Khlebnikov A.G., Shishkin Yu.N., Influence of Alumina Particles' Phase Transition on Its Radiation in the Middle Infrared and Ultraviolet Regions of Spectrum. AIAA 2000-0735.

[8] Rodionov A.V. A Godunov's method modification for prediction of supersonic reacting turbulent jets. La Recherche Aerospatiale, 1995, No 4, p.p. 263-276.

[9] McBride B.J., Gordon S., Reno M.A., Coefficients for Calculating Thermodynamic and Transport Properties of Individual Species, NASA Technical Memorandum 4513, October 1993. 